\title{
Spontaneous Synchronous Synaptic Calcium Transients in Cultured Cortical Neurons
}

\author{
Timothy H. Murphy, ${ }^{1}$ Lothar A. Blatter, ${ }^{3}$ W. Gil Wier, ${ }^{3}$ and Jay M. Baraban ${ }^{1,2}$ \\ 'Departments of Neuroscience, and ${ }^{2}$ Psychiatry and Behavioral Sciences, Johns Hopkins University School of Medicine, \\ Baltimore, Maryland 21205 and 'Department of Physiology, University of Maryland School of Medicine, Baltimore, \\ Maryland 21201
}

The firing pattern displayed by neuronal aggregates is thought to play a key role in cortical development and physiology. In this study, we have employed optical recording of intracellular calcium to monitor activity of multiple neurons simultaneously in primary cortical cultures. With this approach, we have observed spontaneous synchronous calcium transients among adjacent cortical neurons. These transients appear to be mediated by prominent spontaneous synaptic excitation, as they are enhanced by picrotoxin, a blocker of inhibitory GABAergic transmission, and reduced by antagonism of glutamate receptors or addition of TTX. After picrotoxin treatment, the calcium transients exhibit regular frequency and amplitude, and occur in synchrony with bursts of excitatory synaptic potentials every 10-20 sec. Using electrical stimulation, we have identified a relative refractory period, extending up to $5 \mathrm{sec}$ after a synchronous burst, that may play a role in cell synchronization. NMDA receptor antagonists or reduced extracellular calcium levels lower the amplitude of the calcium transients yet fail to alter their frequency, suggesting that intracellular calcium levels may not be a major determinant of burst frequency. In contrast, mild depolarization with kainic acid $(0.5-1 \mu \mathrm{M})$ increased burst frequency up to fivefold, suggesting a critical dependence of rhythmic activity on membrane potential. Chronic blockade of electrical activity with TTX beginning a few days after plating of cultures dampens the amplitude and significantly increases the frequency of calcium transients in mature cultures. These studies demonstrate that aggregates of cultured cortical neurons express synchronous firing activity in vitro and that this network activity is dependent in part on neuronal firing during development.

Recent studies have focused attention on the importance of the firing patterns displayed by groups of neurons in the development and physiology of the nervous system. For example, spontaneous, synchronous neuronal discharges have been identified as an important determinant in the development of the visual system (Shatz, 1990). Synchronous firing of retinal ganglion cells

\footnotetext{
Received May 13, 1992; revised July 1, 1992; accepted July 6, 1992.

We thank Darla Rodgers for excellent secretarial assistance. This work was supported by an NRSA Fellowship (T.H.M.), Lucille P. Markey Charitable Trust (J.M.B.), U.S. Public Health Service Grants DA-00266 (J.M.B.) and HL 29473 (W.G.W.), and American Heart Association, Maryland Affiliate, Inc. (L.A.B.). J.M.B. is a Lucille P. Markey scholar.

Correspondence should be addressed to Timothy H. Murphy, Ph.D., Department of Neuroscience, WBSB 908, Johns Hopkins University School of Medicine, 725 North Wolfe Street, Baltimore, MD 21205-2185.

Copyright (C) 1992 Society for Neuroscience $0270-6474 / 92 / 124834-12 \$ 05.00 / 0$
}

early in development may provide spatial and temporal cues that allow for proper eye-specific innervation of the LGN (Meister et al., 1991). Although the retinal ganglion cells of each retina fire synchronously, asynchronous activity between retinas is thought to be the basis of eye-specific segregation. Synchronous electrical activity is also important in development of ocular dominance columns. In a rather elegant experiment, Stryker and Strickland (1984) blocked retinal activity with TTX and then either synchronously or asynchronously activated the optic nerves. They found that ocular dominance columns only developed if the stimuli were asynchronous, providing evidence that segregation of afferent innervation is determined by which neurons are activated together.

Although the timing of presynaptic stimulation is critical for the specificity of synaptic contacts, studies also indicate a role for coincidence of pre- and postsynaptic events in determination of synaptic strength. For example, if retinal stimulation is paired with postsynaptic depolarization of the visual cortex, synaptic strength is enhanced (Fregnac et al., 1988). These findings obey the Hebb rule, which states that when pre- and postsynaptic elements are coactivated, the strength of their connection is enhanced (Hebb, 1949). Accordingly, synchronous activity in groups of target neurons may provide a mechanism to generate proper spatial patterns of innervation. Although synchronous activation of afferent neurons has been studied, whether similar synchronous firing occurs in targets such as the developing cortex is not known.

Cortical neurons grown in primary culture develop extensive processes and form functional synaptic connections, providing an in vitro system to study activity of developing cortical neurons (Dichter, 1978). As optical recording of intracellular calcium transients provides a convenient method to monitor activity in multiple neurons simultaneously and provides information about an important second messenger, we have applied this approach to primary cortical cultures. We report that synchronous neuronal activity can develop in vitro and that expression of this phenotype is in part dependent on electrical activity during early ontogeny. The synchronous spontaneous activity observed in cultured cortical neurons appears to be different from that found in developing retina (Meister et al., 1991), in that it is produced by synaptic transmission while retinal activity may be propagated via gap junctions.

\section{Materials and Methods}

Cell culture and media. Cell cultures were prepared from day 17 gestation Sprague-Dawley rat fetal cerebral cortex, using a papain (EC 3.4.22.2) dissociation method (Murphy and Baraban, 1990). Cultures were allowed to mature for at least 3 weeks for all experiments. The 
dissociated cells were resuspended at a density of $1.2 \times 10^{6}$ cells $/ \mathrm{ml}$ in minimal essential medium (MEM) supplemented with $5.5 \mathrm{gm} /$ liter glucose, $2 \mathrm{~mm}$ glutamine, $10 \%$ fetal calf serum, $5 \%$ heat-inactivated horse serum, $50 \mathrm{U} / \mathrm{ml}$ penicillin, and $0.05 \mathrm{mg} / \mathrm{ml}$ streptomycin; plated onto polylysine-coated $(10 \mu \mathrm{g} / \mathrm{ml}) 35 \mathrm{~mm}$ culture dishes in $1.5-2 \mathrm{ml}$ of medium, or 12 -well dishes $\left(1 \mathrm{ml}\right.$ medium); and placed in a $37^{\circ} \mathrm{C} \mathrm{CO}_{2}$ buffered incubator. For imaging experiments, cells were plated on polylysine-coated coverslips and placed within six-well plates. The cultures were fed by addition of MEM with $5.5 \mathrm{gm} /$ liter glucose, $5 \%$ heat-inactivated horse serum, and $2 \mathrm{~mm}$ glutamine, after about 4-6, 12-14, 16-17, and 19-21 d in culture, by removal and replacement of approximately $60 \%$ of the medium. Mitotic inhibitors were not added, as glial cell growth was arrested by confluence and the paucity of growth factors in the medium used for feeding. TTX was added directly into the culture medium from a $100 \times$ stock solution.

Immunostaining. Neuron-specific enolase (NSE) immunostaining was performed using polyclonal rabbit antisera obtained from Polysciences (Warrington, PA) as previously described (Murphy et al., 1991b).

Electrophysiology. For electrophysiological measurements, cells were switched to a Hank's balanced salt solution (by triple exchange), which contained, in $\mathrm{mM}, 137 \mathrm{NaCl}, 5.0 \mathrm{KCl}, 2.5 \mathrm{CaCl}_{2}, 1.0 \mathrm{MgSO}_{4}, 0.44$ $\mathrm{KH}_{2} \mathrm{PO}_{4}, 0.34 \mathrm{Na}_{2} \mathrm{HPO}_{4}\left(7 \mathrm{H}_{2} 0\right), 10 \mathrm{Na}^{+}$HEPES, $1 \mathrm{NaHCO}, 0.01$ glycine, and 5 glucose (pH 7.4 and $340 \mathrm{mOsm}$ ). All recordings were made using the whole-cell variant of the patch-clamp technique (Hamill et al., 1981) at room temperature, with glass micropipettes (World Precision Instruments, $1 \mathrm{~B} 120 \mathrm{~F}-4$ ) of $4-8 \mathrm{M} \Omega$ resistance, and an Axopatch $1 \mathrm{C}$ amplifier as previously described (Murphy and Baraban, 1990). The pipette solution used for current-clamp and voltage-clamp experiments contained, in $\mathrm{mM}, 140 \mathrm{~K}^{+}$methyl sulfate, $2 \mathrm{CaCl}_{2}, 11 \mathrm{~K}^{+}$ethyleneglycolbis- $N, N, N, N^{\prime}$-tetraacetic acid, and $10 \mathrm{~K}^{+}$HEPES. Recordings were made in a static bath (1-2 ml) within a $35 \mathrm{~mm}$ tissue culture dish. Agonists and antagonists were applied either by pressure ejection (15-20 psi for $0.5-5 \mathrm{sec}$ ) from $2-6 \mu \mathrm{m}$ tip diameter glass pipettes (compounds diluted into bathing medium) positioned $250-500 \mu \mathrm{m}$ from the cell of interest (previous experiments indicate dilution of up to fivefold; Murphy et al., 1988 ), or by addition directly into the bathing medium at 100 -fold concentration dissolved in bathing medium. Direct addition of bathing medium or water alone ( $20 \mu \mathrm{l}$ to a $2 \mathrm{ml}$ bath) failed to affect ongoing electrical activity or cell stability. 6-Cyano-7-nitroquinoxaline-2,3-dione (CNQX) and (+)MK-801 were from Research Biochemicals (Natick, MA); TTX, picrotoxin, and kainate, from Sigma (St. Louis, MO); (D)2-Amino-phosphonovaleric acid (APV), from Cambridge Research Biochemicals.

Photodiode measurement of fluo-3 fluorescence. Changes in cell calcium were estimated using the fluorescent probe fluo-3 (Minta et al., 1989). In some experiments, fura-2 was used to quantitate intracellular $\mathrm{Ca}^{2+}$ (Grynkiewicz et al., 1985). Flio-3 acetoxymethyl ester (AM) or fura-2 AM (Molecular Probes, Eugene, OR) was dissolved in dimethyl sulfoxide at $5 \mu \mathrm{g} / \mu \mathrm{l}$ and further diluted into Hank's balanced salt solution at $10 \mu \mathrm{g} / \mathrm{ml}$ in the presence of $0.25 \%$ pluronic F-127. Cortical neurons were incubated with these solutions for $1 \mathrm{hr}$ at room temperature. Cells were then washed two times with Hanks's balanced salt solution and observed under epifluorescence ( $490 \mathrm{~nm}$ excitation) at room temperature. Fluorescence was quantitated using an EG and G Ortech photodiode (UV040BQ), amplified by an Axopatch $1 \mathrm{C}$ amplifier, and displayed by a strip chart recorder. In some experiments a photomultiplier tube (Nikon P1) was used, as indicated. A cardboard mask was placed between the cells and the photodiode tube to reduce the area illuminating the photodiode to $\approx 1000 \mu \mathrm{m}^{2}$ (approximately three neuronal cell bodies). In experiments using the photomultiplier tube, an adjustable rectangular diaphragm was used to reduce the area of illumination to 100 $\mu \mathrm{m}^{2}$ (an area within a neuronal cell body). A neutral density filter was added to reduce photobleaching, and the fluorescence field diaphragm was lowered, allowing fluorescence illumination of only the cells being imaged. To prevent further photobleaching, a shutter was added to the fluorescence lamp. The shutter was typically open for $30 \mathrm{msec}$ every second, which accounts for the broken lines present in the indicated records. Synaptic $\mathrm{Ca}^{2+}$ fluxes were stable for at least $10 \mathrm{~min}$ of continuous illumination at the above shutter rate. However, during experiments involving prolonged incubation with drugs, care was taken to limit fluorescence illumination to intervals of data collection. Fluorescence background was determined in areas of the culture lacking neurons, and subtracted from all records shown. Results are expressed in units of $\Delta F / F$, where $F=$ baseline fluorescence in the presence of neurons minus non-neuronal background culture fluorescence. Therefore, a $\Delta F /$
$F$ value of 1 would correspond to a $100 \%$ increase in baseline fluorescence.

Imaging of fluo-3 fluorescence. The experimental procedures for digital imaging of $\left[\mathrm{Ca}^{2+}\right]_{i}$ with fluorescent intracellular indicators has been previously described in detail (Blatter and Wier, 1990; Wier and Blatter, 1991). Briefly, the main components of the system are a Nikon Diaphot inverted microscope, a charge-coupled device camera fiberoptically coupled to a microchannel plate intensifier, and a real-time image processor (series 151, Imaging Technology, Inc., Woburn, MA) under the control of a microcomputer. Images obtained at video frame rate $(30 \mathrm{~Hz})$ were stored during the experiment on a real-time video disk storage system (model 8300 RTD, Applied Memory Technology, Tustin, CA). Computer programs for data acquisition and analysis were written using the programming language $\mathrm{C}$ and the library of subroutines from the series 151, ITEX 151. Changes in $\left[\mathrm{Ca}^{2+}\right]_{i}$ measured with the indicator fluo-3 are expressed as $\%\left(F-F_{0}\right) / F_{0}$, where $F$ refers to the fluo-3 fluorescence measured from the cell and $F_{0}$ represents the fluorescence of the cells presumably at rest. Dividing the $F$ images by an $F_{0}$ image provides correction for differences in path length, shading, and fluo-3 concentration. Since the neuronal cultures show some asynchronous spontaneous activity (see Results), it was not possible to record an $F_{0}$ image in which all cells were simultaneously at rest. Therefore, we chose to create a synthetic $F_{0}$ image from the lowest fluorescence values at any given image coordinate within an experiment. $\left[\mathrm{Ca}^{2+}\right]_{i}$ is expressed as the percentage change of fluo-3 fluorescence as compared to the lowest value measured during an experiment at any particular location in the image. To improve the signal-to-noise ratio, images were spatially filtered by averaging a matrix of $2 \times 2$ pixels and then by averaging four successive video frames.

Fluorescence changes occurring in one cell soma may be recorded as out-of-focus fluorescence from the soma of another cell, in which changes in fluorescence may or may not be occurring. This would make it appear that the activity of the two was correlated. However, measurement of the point-spread function of the microscope used demonstrated that the amplitude of light from a point source has fallen to less than $5 \%$ of its peak at a radius of $1 \mu \mathrm{m}$ within the focal plane, and to less than $5 \%$ of that peak in planes $1 \mu \mathrm{m}$ above and below. Thus, cells at a radial distance of greater than $1 \mu \mathrm{m}$ would have only a very small contribution of fluorescence from a neighboring active cell.

Electrically evoked synaptic calcium transients. Fluo-3-loaded cultures were stimulated with a bipolar tungsten electrode placed over, but not in contact with, a group of neurons $\approx 1000 \mu \mathrm{m}$ away from the cells under study (Murphy ct al., 1991a). Fluo-3 fluorescence was measured by photodiode as described above, with the exception that some records were taken during continuous fluorescent illumination (as indicated), with stimulation occurring $100 \mathrm{msec}$ after shutter opening. Stimulation parameters were typically $20-200 \mu \mathrm{sec}$ in duration and 40-90 V.

Statistics. All results unless indicated are the means \pm standard error of the mean (SEM) of at least three separate experiments, usually performed on cultures obtained from separate cell platings. $n$ refers to the number of separate experiments performed, unless indicated otherwise. Data were analyzed by paired $t$ test to examine potential group differences.

\section{Results}

\section{Spontaneous calcium transients in neurons}

As cortical neurons mature over a period of 2-3 weeks in primary culture, they form functional synapses and exhibit spontaneous synaptic activity. By using the calcium-sensitive probe fluo-3 (Minta et al., 1989) and digital imaging techniques, we have observed spontaneous intracellular calcium $\left(\left[\mathrm{Ca}^{2}\right]_{i}\right)$ transients in primary cortical cultures (Fig. 1). As agonist-induced and spontaneous calcium transients have been previously reported in cultured glial cells (Cornell-Bell et al., 1990; CornellBell and Finkbeiner, 1991), we first sought to determine whether the spontaneous calcium transients are present in neurons. To this end, we have processed cultures for NSE immunocytochemistry (Marangos et al., 1979) following calcium-imaging experiments. NSE immunocytochemistry revealed that the cell bodies displaying spontaneous calcium transients were almost entirely NSE positive (Fig. 1). 

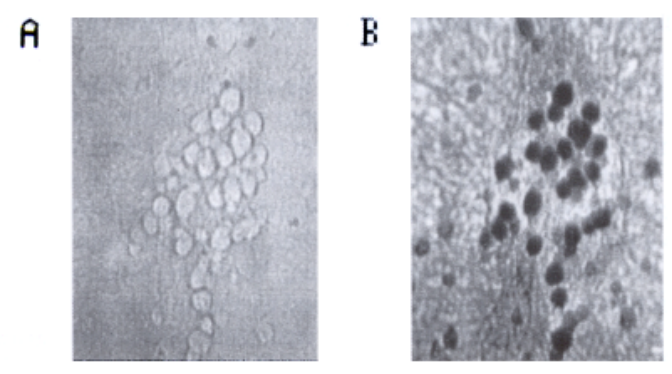

C

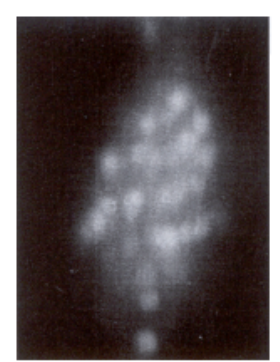

II

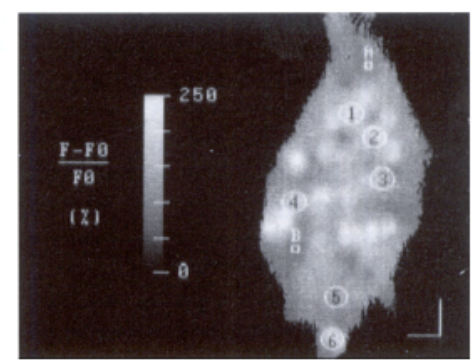

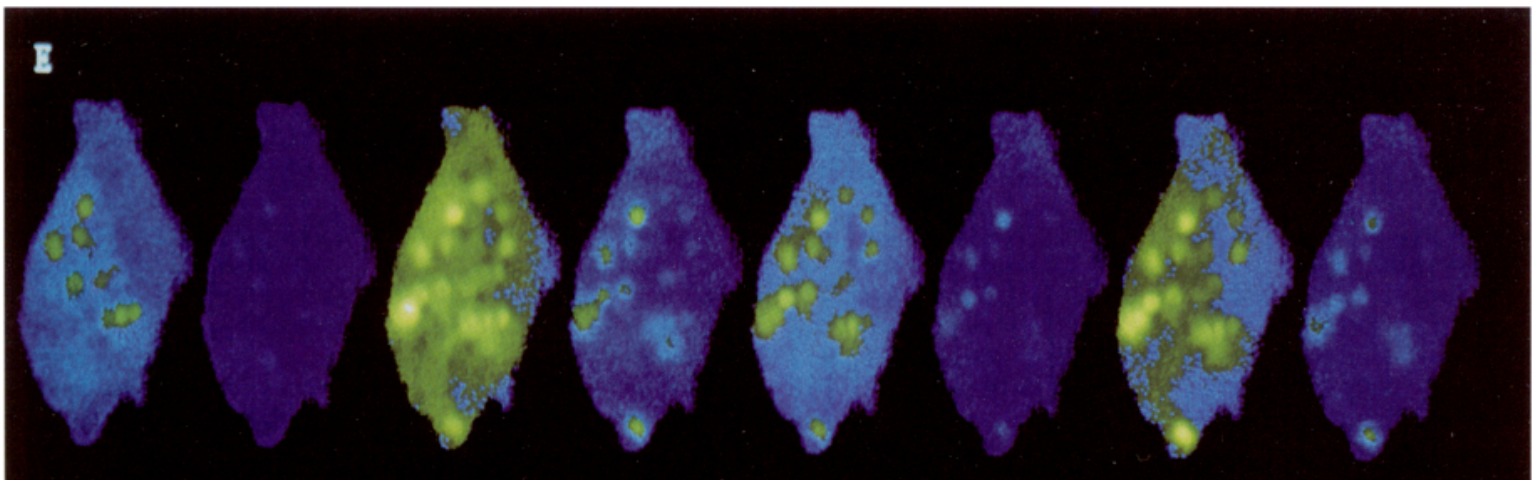

F
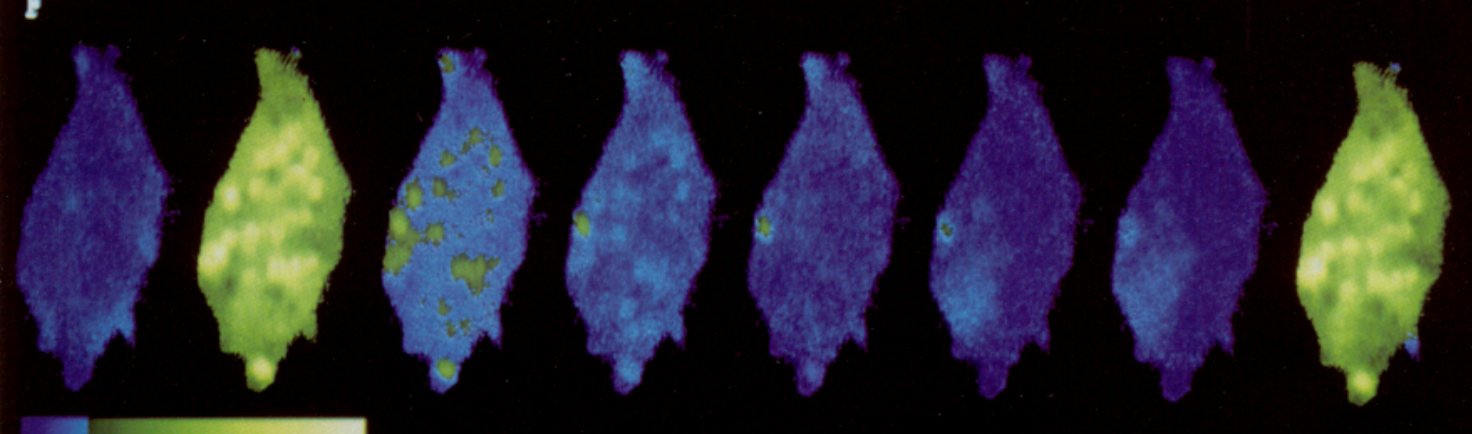

G

H

I

J

control

+ picrotoxin

+ TTX

$+T T X$

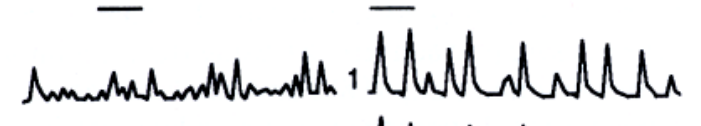

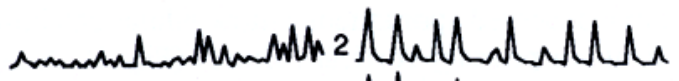

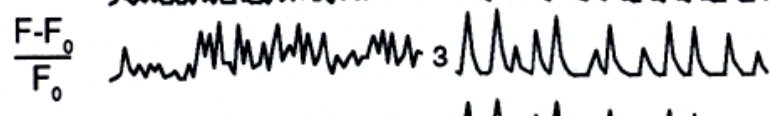

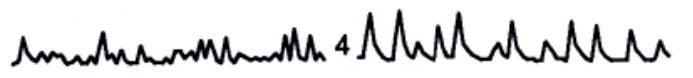

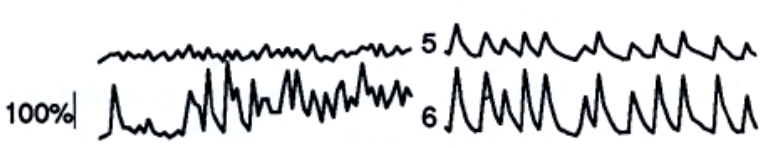

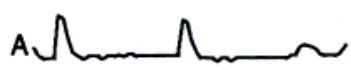

B. $\Lambda$ 
Analysis of fluorescence images indicated synchronous calcium transients within groups of neurons. Although the spontaneous intracellular calcium $\left(\left[\mathrm{Ca}^{2+}\right]_{i}\right)$ transients appear to be synchronous to a large extent (see Fig. $1 E, G$ ), detailed analysis of the fluorescence images revealed that individual neurons can show calcium spiking that is partially asynchronous from the rest of the cell group. In Figure $1 G-1$, we have selected six individual cells from a group of 23 cells that had been positively identified as neurons by NSE immunocytochemistry. These cells were specifically selected to show both synchronous and asynchronous calcium transients by performing a cross-correlation analysis of the amplitudes of the calcium transients of all cells, and then selecting the ones with the lowest correlation coefficients (Fig. 2). (A smaller correlation coefficient was employed as an indicator of asynchronous activity.) Figure $2 A$ shows a correlation matrix for these six cells as well as the average of the cell group ( $n=23$ cells) under control conditions. The characteristics of the microscope used suggest that out-of-focus fluorescence from one cell cannot account for its apparent synchrony with its neighbor (see Materials and Methods). Figure 3 illustrates an experiment in which $\left[\mathrm{Ca}^{2+}\right]_{i}$ was measured with the ratiometric calcium indicator fura-2, which permits quantification of the changes in $\left[\mathrm{Ca}^{2+}\right]_{i}$. Under control conditions, $\left[\mathrm{Ca}^{2+}\right]_{i}$ oscillated at a frequency of $4-5$ spikes/min with an average peak around $200 \mathrm{~nm}$ (Fig. $3 A$ ).

As these calcium transients occurred in neurons, we examined whether they were the consequence of excitatory synaptic transmission. Support for a synaptic mechanism was obtained by simultaneous measurement of spontaneous electrical activity and $\mathrm{Ca}^{2+}$-induced fluo- 3 fluorescence in adjacent neurons $\approx 200$ $\mu \mathrm{m}$ apart. These combined recordings indicate that $\left[\mathrm{Ca}^{2+}\right]$ transients in one neuron were often coincident with bursts of neuronal activity in its neighbor (Fig. 4A). Furthermore, addition of TTX greatly reduced the fast, spontaneous calcium transients in neurons identified by NSE immunocytochemistry (Fig. 1). Low-amplitude TTX-insensitive spontaneous calcium transients were apparent in a few neurons (Fig. $1 I$ ). These transients displayed distinctly slower kinetics. In the absence of TTX, neuronal calcium transients usually peaked in 1-2 sec; in the presence of TTX, calcium transients took 4-6 sec to reach peak amplitude.

To examine better the relationship between synaptic activity and calcium transients, we indirectly increased the excitatory component of synaptic transmission by reducing GABAergic inhibition with the antagonist picrotoxin $(10 \mu \mathrm{M})$. In all experiments performed, this treatment resulted in increases in am- plitude of calcium transients within $15 \mathrm{~min}$ of exposure $(n=$ 10 ). In the experiment shown in Figure 3, the amplitude of spontaneous calcium transients increased from $200 \mathrm{nM}$ to approximately $500 \mathrm{nM}$ following treatment of the cell with picrotoxin. Population data from the 23 neurons in Figure 1 revealed that picrotoxin treatment led to a highly significant increase $(P<0.001$, paired $t$ test $)$ in average peak amplitude. In control cultures, the average peaks were $101 \pm 37 \%( \pm S D)$ of basal fluorescence levels ( $n=397$ peaks); in picrotoxin, the amplitude of the peaks increased to $133 \pm 47 \%$ of resting levels ( $n=267$ peaks). In picrotoxin-treated cultures, neurons within a group always exhibited synchronous calcium transients with regular periodicity (see Fig. $1 F$ ). Even individual neurons that showed partially asynchronous $\left[\mathrm{Ca}^{2+}\right]_{i}$ transients in the absence of picrotoxin (Fig. 1 $G$ ) became synchronized (Fig. $1 H$ ). Figure $2 B$ shows that after exposure to picrotoxin, all correlation coefficients (see above) increased substantially, indicating increased synchronization of the calcium transients within the cell group. (For the six cells shown, the average correlation coefficient $r$ increased from 0.742 to 0.966 .) Visualization of neurons at low power revealed that groups of neurons as distant as 2 $\mathrm{mm}$ apart were synchronized (data not shown). Addition of TTX blocked the calcium transients in almost all identified neurons (Figs. $1 I, 3 C$ ), whereas in areas of the culture that did not stain positively with NSE, calcium transients could still be observed (Fig. $1 J$ ). In picrotoxin, simultaneous recordings of spontaneous electrical activity measured under whole-cell voltage clamp or current clamp and of $\left[\mathrm{Ca}^{2+}\right]_{i}$ by photodiode in neighboring neurons (50-200 $\mu \mathrm{m}$ apart) demonstrated that the calcium transients and excitatory currents or potentials were synchronized in all neuron pairs examined (Fig. $4 B ; n=10$ ). Spontaneous synchronous calcium transients and currents persisted in picrotoxin-treated culturcs for up to $4 \mathrm{hr}$ and were fully reversible, suggesting that they were not the result of cytotoxicity (data not shown).

\section{Mechanism of rhythmic calcium transients}

In a variety of excitable cell types including thalamic neurons (Deschenes et al., 1984; Jahnsen and Llinas, 1984), skeletal muscle (Purves and Sakmann, 1974), and molluscan neurons (Benson and Adams, 1987), pacemaker potentials can play a major role in the generation of rhythmic firing. In contrast, several observations suggest that the spontaneous calcium transients observed in these cultured cortical neurons do not result from intrinsic pacemaker activity within each neuron. The observation that these neurons exhibit rhythmic spontaneous cur-

$\leftarrow$

Figure 1. Images of $\left[\mathrm{Ca}^{2+}\right]_{i}$ transients in cultured cortical neurons loaded with fluo-3. $A$ and $B$, Images of a group of neurons visualized with bright-field illumination before $(A)$ and after $(B)$ staining with NSE antiserum. $C$, Fluorescence image of a fuo-3 AM-loaded cell culture during a burst of calcium spiking in the presence of picrotoxin. The fluorescence was excited at $485 \mathrm{~nm}$, and emission was measured at $530 \mathrm{~nm}$. $D$, [Ca $\left.{ }^{2+}\right]_{t}$ image: background-subtracted fluo-3 fluorescence images (fluorescence $=F$ ) were further processed by subtracting a fluo-3 image of the cell group at rest $\left(F_{0}\right)$ and dividing it by the same image $\left(\left[\mathrm{Ca}^{2+}\right]_{i}\right.$ is proportional to $\left.\left(F-F_{0}\right) / F_{0}\right)$. The background image was recorded under the same conditions from an area of the bath without cells. Residual background was reduced by thresholding the image at a level corresponding to $5 \%$ or less of the maximal image intensity. The numbered circles mark the position of selected neurons that have the time course of their calcium transients plotted in $G-I$. The boxes labeled $A$ and $B$ represent areas from which $\left[\mathrm{Ca}^{2+}\right]_{i}$ transients were recorded that are thought to be of non-neuronal origin (see $J$. Scale bar: $20 \mu \mathrm{m}$ vertically, $20 \mu \mathrm{m}$ horizontally. $E$, $\left[\mathrm{Ca}^{2+}\right]_{i}$ images of spontaneous activity. Images were recorded at 2 sec intervals for 2 min and are averages of four consecutive video frames. Eight consecutive images are shown. $F$, Calcium spiking of the same cell group after incubation with picrotoxin for approximately $15 \mathrm{~min}$. Two bursts of synchronous calcium transients are shown. The color bar indicates percentage changes in fluo-3 fluorescence, showing changes between 0 and $50 \%$ above baseline in graded blue and changes between $50 \%$ and $250 \%$ in graded yellow. $G-I$, Amplitude of fluo-3 fluorescence measured at $2 \mathrm{sec}$ intervals from an area of $5 \times 5$ pixels $\left(20 \mu \mathrm{m}^{2}\right)$ centered on the cells represented by circles in $D$ : spontaneous calcium spiking $(G)$ and calcium transients after addition of picrotoxin $(H)$ and TTX $(I)$, which abolished the neuronal calcium spiking almost completely. The horizontal bars in $G$ and $H$ indicate the time intervals when the images in $E$ and $F$ were recorded. $J$, Calcium transients recorded from areas without neuronal staining (presumed glial cells) in the presence of TTX. 
A

cell 1 cell 2 cell 3 cell 4 cell 5 cell 6 average

(23 cells)

$\begin{array}{lllllllll}\text { cell 1 } & 1 & & & & & & \\ \text { cell 2 } & 0.885 & 1 & & & & & \\ \text { cell 3 } & 0.728 & 0.718 & 1 & & & & \\ \text { cell 4 } & 0.945 & 0.818 & 0.697 & 1 & & & \\ \text { cell 5 } & 0.747 & 0.728 & 0.829 & 0.765 & 1 & & \\ \text { cell 6 } & 0.591 & 0.686 & 0.858 & 0.504 & 0.631 & 1 & \\ \text { average } & & & & & & & \\ \text { (23 cells) } & 0.910 & 0.856 & 0.914 & 0.896 & 0.889 & 0.753 & 1\end{array}$

B

cell 1 cell 2 cell 3 cell 4 cell 5 cell 6 average

( 23 cells)

cell 1

cell 2

cell 3

cell 4

cell 5

cell 6

average

( 23 cells)
1

09931

$0.989 \quad 0.980$

$\begin{array}{llll}0.990 & 0.983 & 0.994 & 1\end{array}$

$\begin{array}{lllll}0.934 & 0.936 & 0.961 & 0.956 & 1\end{array}$

$\begin{array}{lllllll}0.938 & 0.934 & 0.970 & 0.957 & 0.976 & 1\end{array}$

$\begin{array}{lllllll}0.989 & 0.985 & 0.998 & 0.995 & 0.971 & 0.975 & 1\end{array}$
A

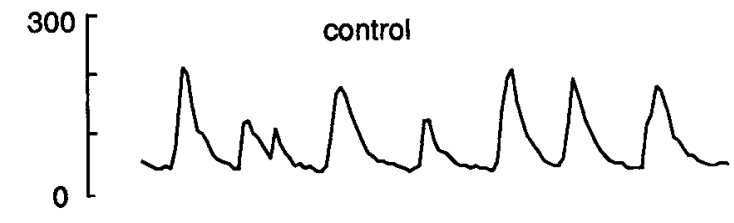

B

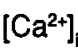

(nM)

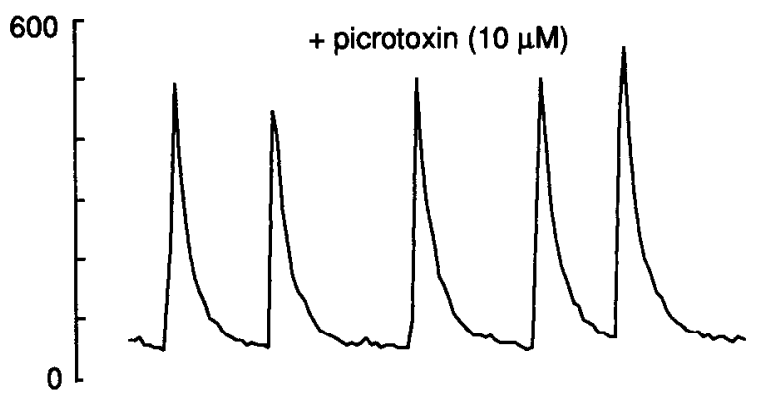

C

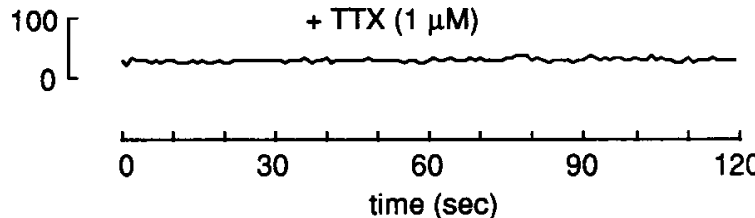

Figure 3. Spontaneous calcium transients measured with fura-2. Fura2 fluorescence was excited at 360 and $380 \mathrm{~nm}$, and emission was measured at $510 \mathrm{~nm}$. The fluorescence was measured with a photomultiplier tube from a small area of approximately $10 \mu \mathrm{m}$ in diameter centered on a neuronal cell body. The cell culture was loaded with the indicator by exposure to fura-2 AM (10 $\mu \mathrm{M}$; see Materials and Methods). The fura-2 signal was calibrated in vitro using a solution containing fura-2 salt and no calcium (EGTA-buffered) or a saturating concentration of calcium, respectively. Background subtraction was achieved by subtracting the amount of fluorescence measured close to the neurons in the absence of oscillations. $A$, Spontaneous $\left[\mathrm{Ca}^{2+}\right]_{\text {i transients under }}$ control conditions. $B$, Following exposure to picrotoxin $(10 \mu \mathrm{M})$ for 15 min, the $\left[\mathrm{Ca}^{++}\right]_{i}$ transients are markedly enhanced. $C$, Addition of TTX $(1 \mu \mathrm{M})$ abolished the oscillations completely.

was placed at least $1 \mathrm{~mm}$ from the observed cell, the electrically evoked response appears to result from synaptically released neurotransmitter, since no response to stimulation was observed in the presence of the glutamate antagonists MK-801 $(10 \mu \mathrm{M}$; Wong et al., 1986) and CNQX (50 $\mu \mathrm{M}$; Honore et al., 1988). Furthermore, the calcium transient evoked by electrical stimulation displayed kinetics similar to those occurring spontaneously (Fig. $5 A$ ). Electrical stimulation of a group of neurons approximately $1 \mathrm{~mm}$ away with supramaximal stimulus intensities readily evoked calcium transients during the interval between bursts in the neuron under observation (Fig. 5A). Furthermore, repeated electrical stimulation (every $10 \mathrm{sec}$ ) was able to override the endogenous bursting mechanisms, as calcium transients followed stimulation frequencies faster than the endogenous rhythm (Fig. 5C). In contrast, lower-frequency stimulation (every $20 \mathrm{sec}$ ) resulted in a return of endogenous burst triggering, punctuated with events triggered by electrical stimulation (Fig. 5C). Thus, if neurons are presented with a strong exogenous pacemaker of similar frequency to their endogenous pacemaker, they will adopt the new pacemaker. When the stimulus intensity was reduced, it was possible to identify a relative refractory period that extends $1-5 \mathrm{sec}$ after the peak of a synaptic calcium transient (Fig. 5A,B). With increased stimulus intensity, the neurons were not refractory, indicating that the refractory period observed is only relative and not absolute (Fig. 5A). The

ability of electrical stimulation of small groups of neurons to

stimulation to activate neurons synaptically during the interval between spontaneous bursts. When the stimulating electrode 
A

Fluo-3 calcium induced fluorescence.
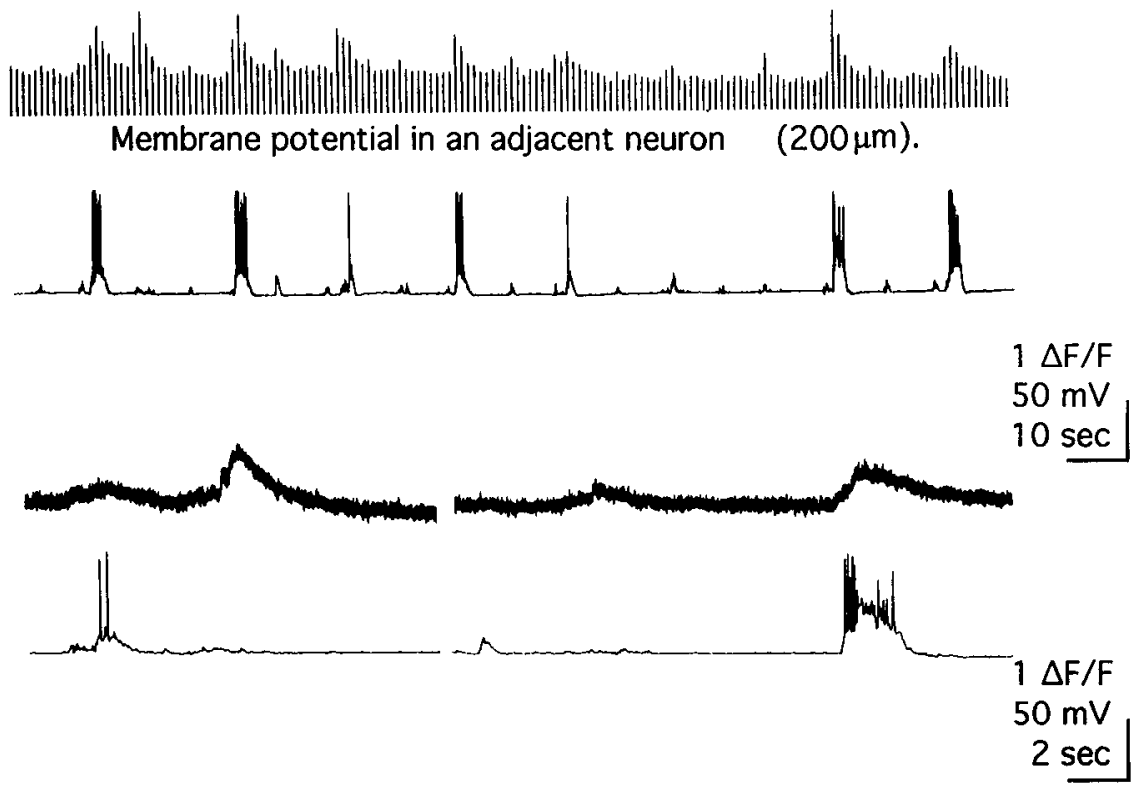

B

Fluo-3 calcium induced fluorescence.

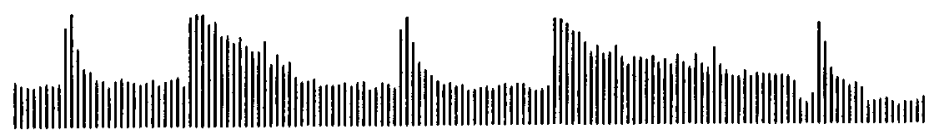

Membrane potential in an adjacent neuron $(200 \mu \mathrm{m})$.
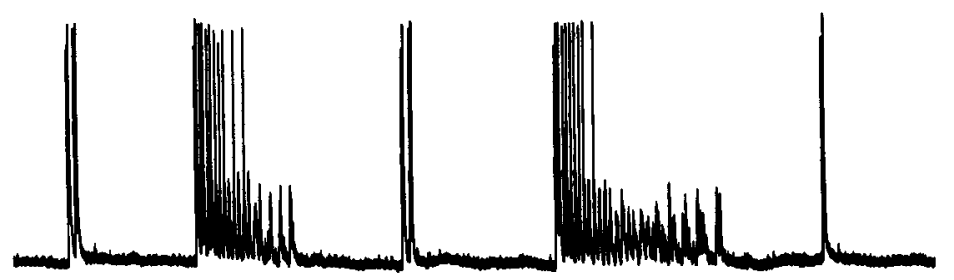

Figure 4. Coincidence of spontaneous excitatory potentials and calcium transients in different neurons. $A$, Calciuminduced fluo-3 fluorescence was measured by photomultiplier tube in a single cortical neuron (described in Materials and Methods). In an adjacent neuron $\approx 200 \mu \mathrm{m}$ away, membrane potential was simultaneously measured under whole-cell current clamp ( -67 $\mathrm{mV}$ resting potential). The broken record of $\mathrm{Ca}^{2+}$-induced fluorescence is due to the shuttering protocol used to prevent photobleaching. The lower two traces are at a faster time scale (same neuron) using continuous illumination. $B$, In the presence of picrotoxin $(10 \mu \mathrm{M}$, $15 \mathrm{~min}), \mathrm{Ca}^{2+}$-induced fluo-3 fluorescence was measured in a single cortical neuron by photodiode. In a different neuron $\approx 200 \mu \mathrm{m}$ away, membrane potential was simultaneously measured under whole-cell current clamp ( -58 $\mathrm{mV}$ resting potential). Records shown in $A$ and $B$ are from different experiments. elicit synchronous calcium transients synaptically suggests that pacemaker activity in a small subpopulation of neurons could be sufficient to drive the rhythmic firing observed.

\section{Role of NMDA receptors}

In previous studies of the effect of picrotoxin on synaptic transmission in these cortical cultures, we have observed synaptic currents that were sensitive to NMDA-type glutamate receptor antagonists (Murphy et al., 1991b). Accordingly, we have examined the role of NMDA receptors in mediating calcium transients in the presence of picrotoxin (Fig. 6A). The NMDA receptor antagonist APV reversibly attenuated the amplitude of picrotoxin-induced calcium transients by greater than $50 \%$ ( $n$ $=5$ ). In a similar manner, the noncompetitive NMDA receptor antagonist MK-801 (3 $\mu \mathrm{M})$ reduced the amplitude of calcium transients $46 \pm 8 \%$, when compared to matched picrotoxintreated controls $(n=4)$. Although NMDA receptor antagonists reduced the amplitude of calcium transients in the presence of picrotoxin, analysis of the residual activity suggested that local application of these agents had little effect on their frequency. Furthermore, after continuous application of MK-801 (3 $\mu \mathrm{M})$ for up to $4 \mathrm{hr}$, the amplitudes of picrotoxin-induced calcium transients were reduced, with no statistically significant effect on burst frequency (MK-801, $4.5 \pm 0.7$ bursts $/ \mathrm{min}, n=10$, vs control, $3.8 \pm 0.2$ bursts $/ \mathrm{min}, n=42$ ). In the presence of combined application of NMDA receptor antagonists with the nonNMDA glutamate receptor antagonist CNQX, no spontaneous or picrotoxin-stimulated calcium transients were observed in neurons, consistent with glutamate being the major excitatory transmitter of these cultures.

To evaluate whether NMDA receptor antagonists reduce calcium transient amplitude by directly blocking calcium influx via the NMDA receptor or indirectly via a reduction in network polysynaptic activity, we tested their effects on electrically evoked synaptic calcium transients that would be less likely to depend on polysynaptic activity. In these experiments, picrotoxin was 
A

\section{$60 \mathrm{~V}$ Stimulation}

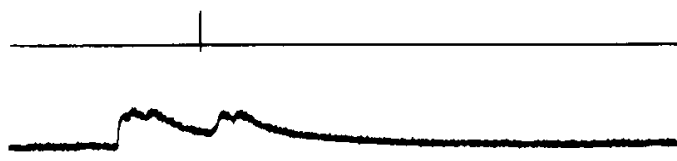

$50 \vee$ Stimulation

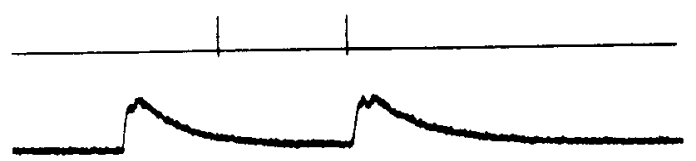

$2 \mathrm{sec}$

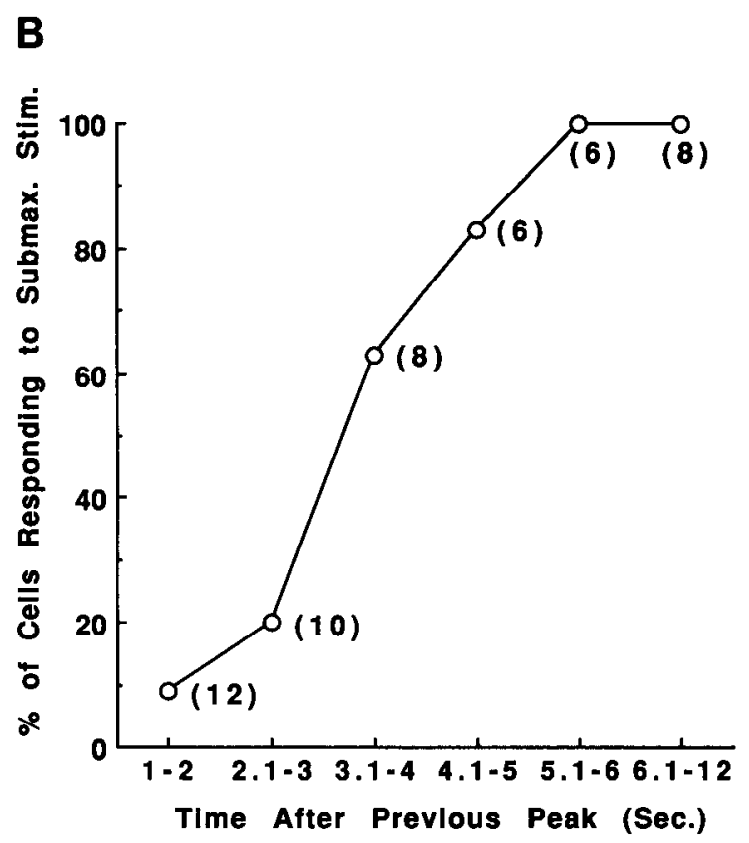

C
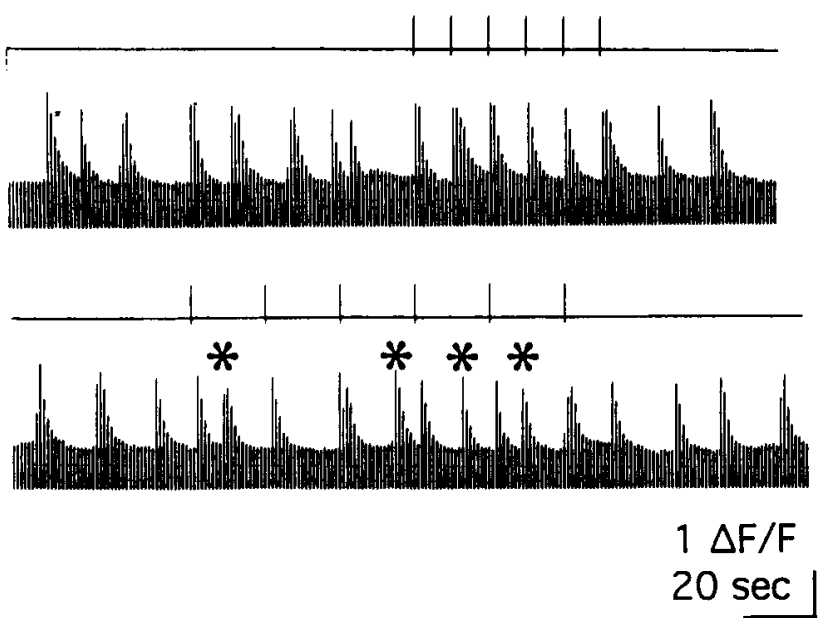

used to enhance the amplitude of the electrically evoked synaptic calcium transients. In the presence of picrotoxin, electrically evoked calcium transients were attenuated by the NMDA receptor antagonist APV $(n=4)$, suggesting that NMDA receptors may directly mediate a component of postsynaptic calcium entry (Fig. 6B).

\section{Effects of membrane potential and intracellular calcium}

Two common determinants of pacemaker frequency in neurons are intracellular calcium levels and membrane potential. We have tested the role of these parameters in cortical cultures by providing mild depolarization with low concentrations of the glutamate receptor agonist kainate and by reducing extracellular calcium levels. In these experiments, picrotoxin-treated neurons exhibited the typical $4.5 \pm 0.3$ calcium bursts $/ \mathrm{min}$. Addition of 0.5-1 $\mu \mathrm{M}$ kainate (Fig. $7 A$ ) significantly increased the frequency of bursts to $23 \pm 2.9$ bursts $\min (P<0.05 ; n=4)$. The increased bursting was totally suppressed by the addition of 1 $\mu \mathrm{M}$ TTX. These findings suggest that depolarization produced by kainate brings neurons closer to the threshold for action potential generation, resulting in an increase in burst frequency.

Intracellular calcium levels have been shown to affect pacemaker activity in a variety of systems. To address the role of intracellular calcium levels in setting burst frequency, we reduced extracellular calcium levels to $500 \mu \mathrm{M}$ and increased extracellular $\mathrm{Mg}^{2+}$ from 1 to $2 \mathrm{~mm}$. Under these conditions, spontaneous synaptic calcium transients of reduced amplitude and duration were present (Fig. 7B). Although the amplitude of the spontaneous calcium transients was reduced, their frequency (4 $\pm 0.4 \mathrm{burst} / \mathrm{min}$ ) in low $\mathrm{Ca}^{2+}$ when compared to controls (3.6 $\pm 0.4 ; n=8$ ) was not significantly altered. Furthermore, restoration of extracellular $\mathrm{Ca}^{2+}$ and $\mathrm{Mg}^{2+}$ levels $(2.25$ and $1 \mathrm{~mm}$, respectively) resulted in a large increase in amplitude and duration but not frequency. Since reducing calcium transient amplitude does not affect burst frequency, peak intracellular calcium levels may not be a major determinant of rhythmic activity. In contrast, the profound increase in burst frequency following

Figure 5. Relative refractory period in neuronal excitability. $A$, Photomultiplier tube record of $\mathrm{Ca}^{2+}$-induced fluo-3 fluorescence from a single cortical neuron. A group of neighboring neurons $\approx 1000 \mu \mathrm{m}$ away were stimulated using a bipolar electrode $(60 \mathrm{~V}, 20 \mu \mathrm{sec})$ just after a spontaneous calcium burst. Timing of stimulus is indicated in the upper bar. At lower stimulus intensity $(50 \mathrm{~V}, 20 \mu \mathrm{sec}$; lower trace), it was possible to identify a relative refractory period in which electrical stimulation failed to produce a synaptic calcium transient. Because of the relatively short exposure time, these records were not shuttered. The $60 \mathrm{~V}$ stimulation was performed after the $50 \mathrm{~V}$ stimulation, and its fluorescence is attenuated because of photobleaching. $B$, The relationship between the time of electrical stimulation and the percentage of cells responding to a submaximal electrical stimulus (numbers by symbols are the number of trials at each time interval). When a maximal stimulus was used, usually over or equal to $60 \mathrm{~V}$, there was never a failure to produce a synaptic $\mathrm{Ca}^{2+}$ transient over the same time intervals, in 21 trials performed in seven different cells, suggesting that the refractory period is relative and not absolute. $C$, Record of evoked and spontaneous calcium transients from a single neuron with maximal electrical stimulation performed at the indicated frequency (upper bar). At stimulus frequencies equal to or higher than the endogenous pacemaker, neurons will follow an exogenous pacemaker. During low-frequency stimulation, evoked calcium transients are punctuated by a return of the endogenous pacemaker $\left({ }^{*}\right)$. All experiments shown in this figure were quantitated by photomultiplier tube and conducted in cultures treated with picrotoxin $(10 \mu \mathrm{M})$. 
A

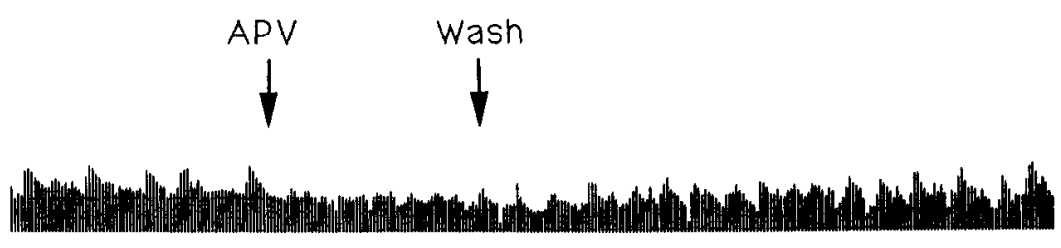

Picrotoxin 15 min
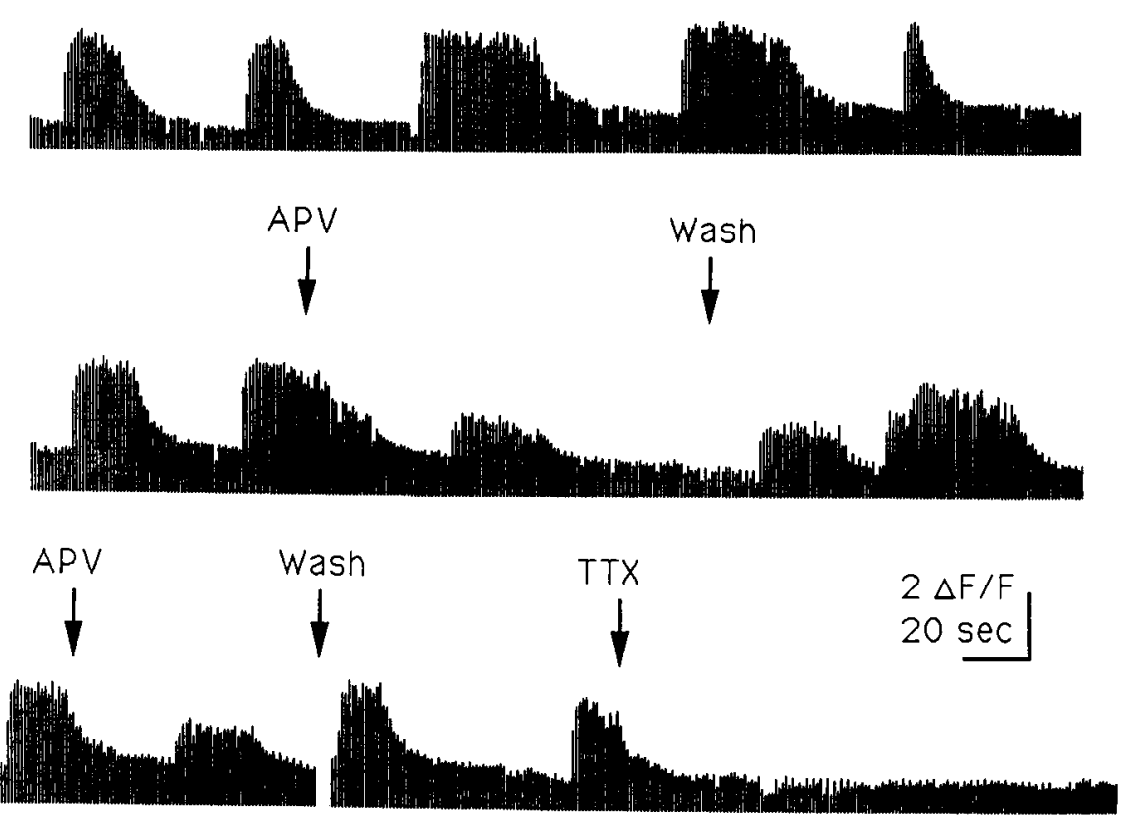

B
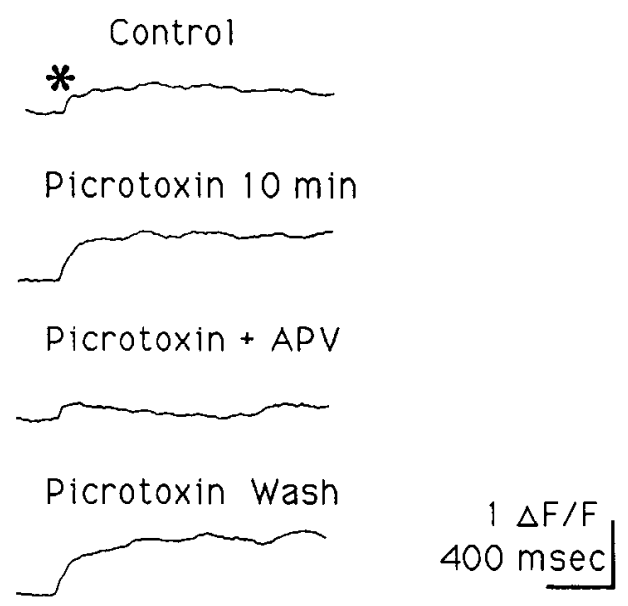

Figure 6. Effect of an NMDA receptor antagonist on calcium transients during picrotoxin treatment. $A$, Tracing shown is a record of fluo-3 calcium-induced fluorescence from two or three clustered cortical neurons. Picrotoxin was added to the bathing medium $15 \mathrm{~min}$ prior to the lower three traces shown. The NMDA receptor antagonist APV $(300 \mu \mathrm{M})$ was applied locally by pressure ejection (1 sec), and its removal was sped up by perfusion with a pipette (wash). TTX $(1 \mu \mathrm{M})$ was added to the bathing medium and not removed. $B$, Continuous photodiode record of fluo3 fluorescence in response to electrical stimulation (see Fig. 5) before and after picrotoxin, in the presence and absence of locally applied APV $(300 \mu \mathrm{M}) . *$, the time of electrical stimulation. mild depolarization with kainate suggests that membrane potential may play a key role in setting pacemaker frequency.

\section{Development of synaptic calcium transients}

As cortical neurons in culture display highly repetitive synchronous discharges, we wondered whether formation of the requisite synaptic circuitry might depend on neuronal activity during synaptogenesis in early development. To test this possibility, we have assessed whether blockade of neuronal activity during development disrupts this characteristic feature of mature cultures. To reduce synaptic activity during development, TTX ( $1 \mu \mathrm{M})$ was added to cultures after 1,7 , or $20 \mathrm{~d}$ in vitro (supplemented every 3-4 d; see Materials and Methods). Wholecell current-clamp records indicated that the ability of neurons to fire action potentials was completely blocked by this treatment, even after TTX was present in culture medium for up to $4 \mathrm{~d}$ (consistent with TTX being stable in culture medium). The effect of exposure to TTX was assessed in cultures maintained 

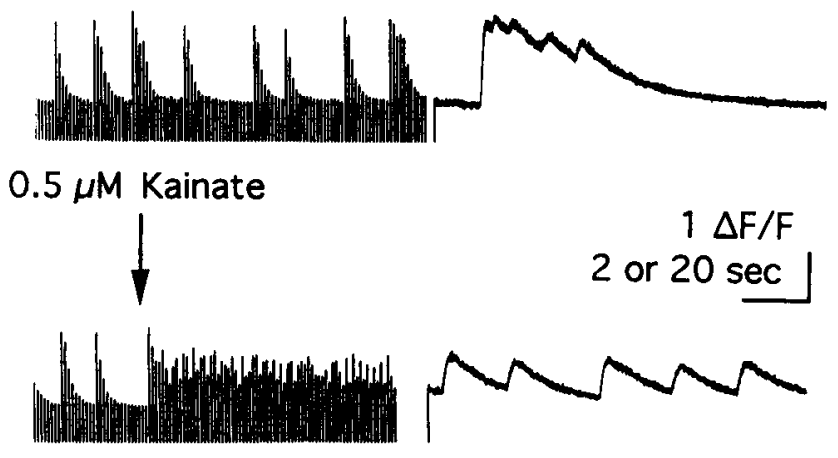

Figure 7. Effect of depolarization and calcium transient size on rhythmic activity: photomultiplier tube records of fluo-3 calcium-induced fluorescence from a single neurons in cultures treated with picrotoxin $(10 \mu \mathrm{M}) . A$, Bath application of a low concentration of the depolarizing agent kainate $(0.5 \mu \mathrm{M}$; added at time indicated by arrow in lower trace) greatly increases the frequency of synaptic calcium transients. Continuous records are shown at the right to illustrate the response at a higher time resolution. $B$, The role of calcium transient size in determining burst frequency was examined by lowering extracellular $\mathrm{Ca}^{2+}$ levels from 2.25 to $0.5 \mathrm{~mm}$ and raising $\mathrm{Mg}^{2+}$ levels from 1 to $2 \mathrm{~mm}$. Although this treatment attenuated the amplitude of the transients, it failed to affect their frequency significantly. The beginning of the record was taken under low $\mathrm{Ca}^{2+}$; the arrows show when the $\mathrm{Ca}^{2+}$ and $\mathbf{M g}^{2+}$ levels were restored to 2.25 and $1 \mathrm{~mm}$, respectively, without significantly affecting burst frequency. The lower trace shows rhythmic activity after approximately $2 \mathrm{~min}$ of $2.25 \mathrm{~mm}$ extracellular

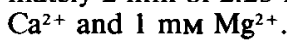

B
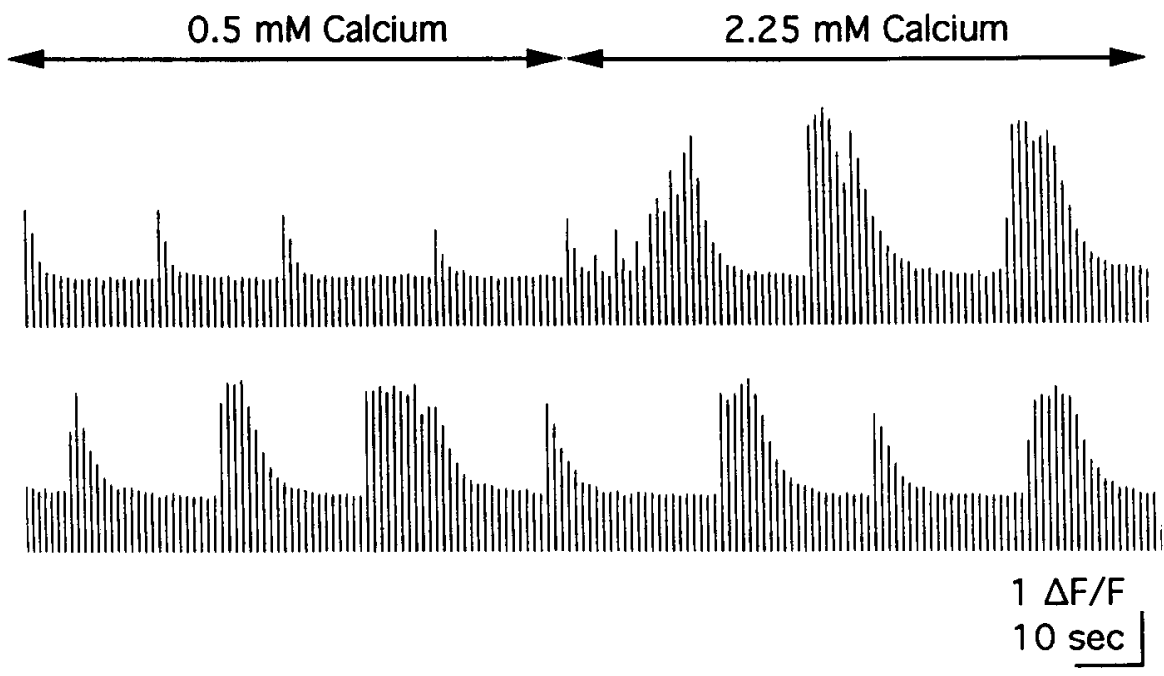

for 21-23 $\mathrm{d}$ in vitro. At this time, TTX was removed by medium exchange $(3 \times)$ and calcium transients were monitored in the presence of picrotoxin (Fig. 8). In untreated cultures, the average frequency of calcium transient bursts in neurons $(n=42)$ from at least six separate platings was $3.8 \pm 0.2 / \mathrm{min}$. Treatment of naive, mature cultures with TTX for $1-2 \mathrm{~d}(3.9 \pm 0.3$ bursts/ $\min ; n=14$ ) did not significantly affect the frequency or amplitude of picrotoxin-induced calcium transients when compared to untreated controls. In contrast, addition of TTX for 2 weeks, from days 7 to 21 , reduced the amplitude of calcium transients while their frequency was significantly increased $(9.6$ $\pm 1.2 \mathrm{bursts} / \mathrm{min} ; n=41$ ). With more prolonged TTX treatment, starting on the first or second day after plating prior to the appearance of spontaneous activity (Murphy et al., 1991b), and maintained for the next $20 \mathrm{~d}$, the calcium transients were reduced in amplitude to near background levels yet increased in frequency by up to 10 -fold $(35.4 \pm 7.8 / \mathrm{min} ; n=6)$. Wholecell voltage- and current-clamp records indicated that the small synaptic calcium transients coincided with a high frequency of inward currents and neuronal firing (Fig. 8). Measurement of membrane potential and calcium in adjacent neurons indicated that cell synchrony is preserved in cultures treated chronically with TTX ( $n=3$ cell pairs). The presence of synchronous discharges in cultures treated with TTX prior to synapse formation suggests that this network activity may not be critically dependent on electrical activity during synaptogenesis and that it is rapidly established upon restoration of neuronal activity. Although synchronous activity was still apparent in cultures treated chronically with TTX, the high frequency of discharges contrasts greatly with the intermittent bursts of action potentials followed by silent periods observed in control neurons (Fig. 4B).

Cultured spinal cord neurons (Brenneman et al., 1983) and retinal ganglion cells (Lipton, 1986) are dependent on spontaneous electrical activity for survival. After measurement of calcium transients, TTX-treated and control cultures were fixed and stained with NSE antibody. Cell counts indicated that TTX treatment did not produce a statistically significant reduction in the number of NSE-positive cells present in cortical cultures (4 $\pm 7 \%$ cell loss in three separate experiments with at least 2 weeks of TTX exposure). However, we cannot exclude that a small subpopulation of neurons important in regulating pacemaker activity may be lost with TTX treatment.

\section{Discussion}

Using calcium-sensitive fluorescent probes, we have observed synchronous calcium transients within groups of cultured cortical neurons. Addition of both NMDA and non-NMDA glutamate receptor antagonists completely blocked all spontaneous 
A

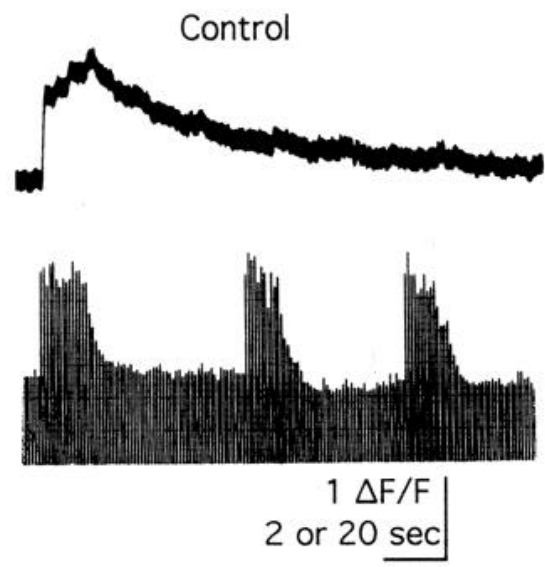

Chronic TTX 14 days
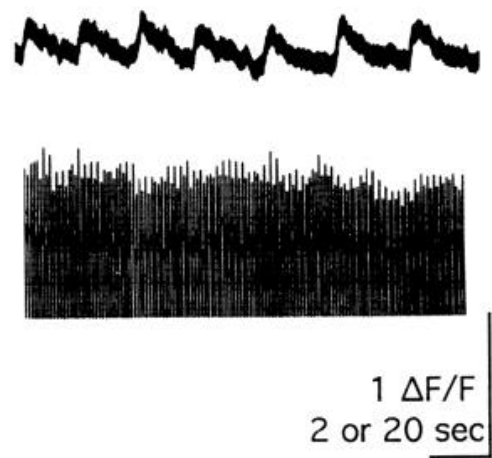

B

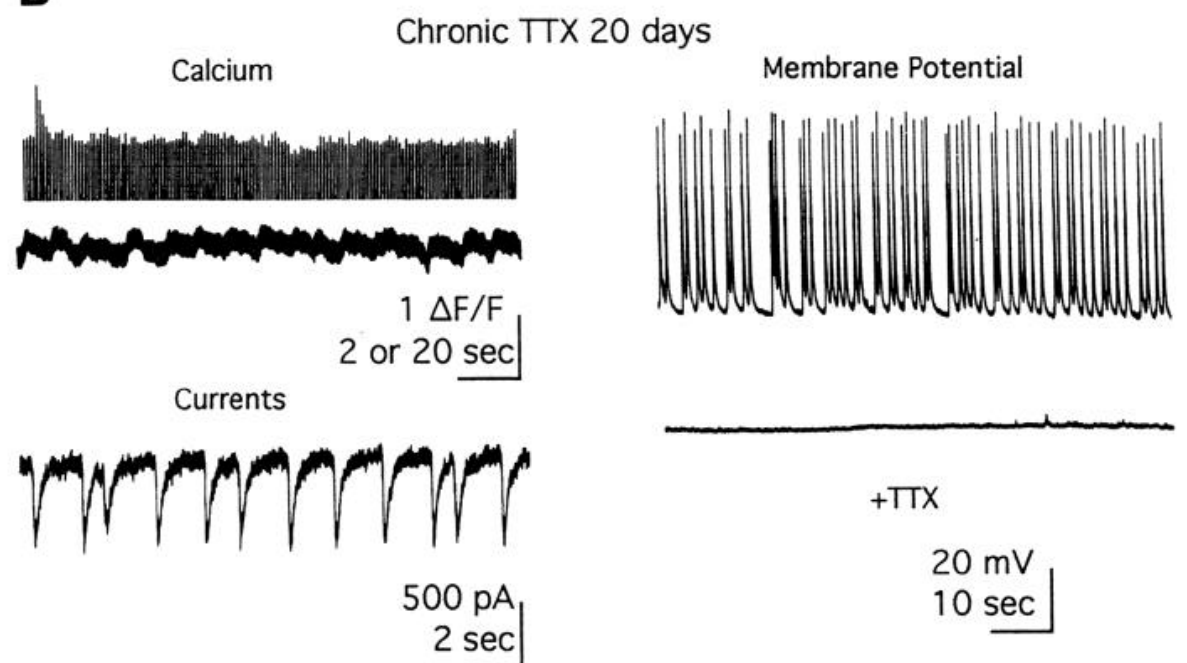

Figure 8. Blockade of synaptic activity during development alters the phenotype of calcium transients in mature neurons. Shown are photodiode records (from single neurons) of spontaneous calcium transients. $A$, Control cultures ( $21 \mathrm{~d}$ in culture) and cultures treated with TTX since day 7 in culture and removal at day $21 . B$, TTX treatment since day 1 in culture and removal at day 21 . Whole-cell current- and voltage-clamp records for day 1 TTX treatment were performed as described in Materials and Methods ( $-60 \mathrm{mV}$ holding potential). As expected, readdition of TTX completely blocked spontaneous firing. Picrotoxin $(10 \mu \mathrm{M})$ was added to all cultures at least $15 \mathrm{~min}$ before recording.

electrical activity and calcium transients in neurons, suggesting that these calcium transients are driven by synaptic activity. In contrast, synchronous spontaneous activity in the retina (Meister et al., 1991) does not appear to be dependent on transmitter release, but is thought to be propagated via gap junctions. We have examined whether cortical neurons in this preparation are coupled through gap junctions by inclusion of the dye Lucifer yellow in patch pipettes (Baraban et al., 1992). Although astrocytes in this culture system exhibited extensive "dye coupling," dye was not passed from one neuron to another, suggesting that synchronous neuronal activity is not dependent on electrical coupling.

In many excitable cell types, such as the neurons of the thalamus, pacemaker potentials determine the onset of neuronal firing (reviewed in Pedley and Traub, 1990). Whole-cell currentand voltage-clamp recordings indicated that membrane potential or current is stable during the interval between excitatory bursts, arguing against pacemaker potentials. Pacemaker potentials were also absent from records of spontaneous synchronous activity observed in cultured hippocampal neurons (Peacock, 1979), cultured spinal cord neurons (Barker and MacDonald, 1980), and isolated cortex (Hablitz, 1987). However, we cannot exclude the possibility that pacemaker potentials dependent on diffusible cytoplasmic components may have been "washed out" in whole-cell recording mode. Alternatively, a small minority of neurons may possess pacemaker potentials and set the frequency of firing for the culture. Consistent with this proposal, Misgeld and Swandulla (1989) report that less than 5\% of cultured hypothalamic neurons direct rhythmic firing of the general population. Furthermore, Miles and Wong (1983) reported that in some cases activation of only a single CA3 neuron is sufficient to produce a population response. Another possible determinant of neuronal synchrony is a refractory period after firing (Gutnick et al., 1982; Traub et al., 1984). By using electrical stimulation, we found that it is possible to produce a synaptic calcium transient at any time during the interval between spontaneous bursts, suggesting that neurons are not absolutely refractory. In fact, neuronal calcium transients present in cultured cortical neurons can follow the exogenous stimulus at rates up to fivefold higher than their endogenous pacemaker (data not shown). Under these conditions, endogenous triggering of calcium bursts was completely suppressed. However, at lower stimulus intensities it was possible to identify a relative refractory period that extended 1-5 sec after the peak calcium spike. Thus, a decrease in neuronal excitability in the interval after a burst may contribute to establishing synchronous bursting. 
Although NMDA receptor antagonists reduced the amplitude of picrotoxin-induced calcium transients, they failed to affect their frequency significantly. These data suggest that the interval between transients may not be set by inhibitory processes linked to peak intracellular calcium levels. These results are, in part, consistent with those of Fields et al. (1991), who showed that spontaneous network synaptic activity in cultured spinal cord neurons was suppressed by the addition of NMDA antagonists. To investigate further the role of intracellular calcium concentration in determining discharge frequency, we decreased extracellular calcium levels. Although the amplitude and duration of spontaneous calcium transients were reduced, this maneuver did not significantly affect the frequency of spontaneous discharges or calcium levels during the interval between bursts. These data suggest that peak intracellular calcium concentration may not be the primary regulator of spontaneous firing in these cortical neurons. However, we cannot rule out that the intracellular calcium concentration during the interval between bursts may be an important determinant of burst frequency. By contrast, mild depolarization by glutamate receptor agonists produced a robust increase in the frequency of synaptic calcium transients (Fig. $7 A$ ). The ability of mild depolarization to elevate discharge frequency significantly is consistent with previous models and observations of network synaptic activity (for review, see Dichter and Ayala, 1987; Pedley and Traub, 1990). By bringing cells closer to threshold, mild depolarization would be expected to shorten the interval between spontaneous bursts.

Recent evidence suggests that formation of synaptic connections involves two discrete components, initial targeting and physical contact (Cox et al., 1990; Fraser and Perkel, 1990), thought to involve trophic factors and cell adhesion, followed by a period of plasticity that is dependent on synaptic activity (Meyer, 1983; Schmidt and Edwards, 1983). To test whether similar events are involved in expression of synchronous calcium transients in mature neurons, we treated cultures with TTX to block electrical activity during development in vitro. Remarkably, when TTX was removed and picrotoxin added to chronically treated cultures, synchronous synaptic activity still occurred despite the presence of TTX during synapse formation. Modeling studies by Traub et al. (1984) indicating that a randomly wired neuronal network can generate patterned synchronous discharges may help account for this result.

Analysis of records from cultures treated chronically with TTX indicated that calcium transients coincident with electrical activity occur at higher frequency than in control cultures. Accordingly, it appears that the frequency of synchronous activity can be modulated by neuronal activity in early development. Our results suggest that this alteration is probably not secondary to altered neuronal survival, but likely reflects a change in the physiological properties of these neurons due to blockade of activity. Purkinje cells grown in TTX display marked alteration in dendritic length and branching (Schilling et al., 1991); conceivably similar morphological changes contribute to the different firing pattern observed in cortical cultures. Previous studies by Furshpan and Potter (1989) indicate that prolonged cxposure of neurons to glutamate receptor antagonists resulted in seizure-like activity when the compounds were removed. This activity was characterized by intense synaptic discharges resulting in prolonged depolarization and cell death. In our study with TTX, we observe an increase in the frequency of synaptic activity without prolonged depolarization or toxicity. In the presence of TTX, we have observed spontaneous low-amplitude synaptic currents. Perhaps the milder effects of TTX treatment may stem from a persistent low level of glutamate receptor stimulation that occurs due to spontaneous transmitter release.

A remarkable feature of the spontaneous calcium transients in cortical neurons is their relatively constant frequency. Despite data being derived from multiple platings of cells, the frequency of spontaneous calcium transients usually ranged between 3 and 6 bursts/min. The highly patterned nature of the spontancous activity in cortical cultures suggested that this activity may be a common feature in the developing nervous system. Measurement of electrical activity in neonatal cortex in vivo suggests the presence of low-frequency spontaneous discharges that may resemble events in cortical cultures. EEG activity in the mature mammal is primarily composed of $8-12 \mathrm{~Hz}$ activity. In contrast, in neonatal rats, EEG activity is of smaller amplitude and lower frequency (Snead and Stephens, 1983). EEG recordings from the cortex of fetal guinea pigs indicate slow synchronous rhythmic spiking (Flexner et al., 1950). Single-unit recordings from neonatal kittens indicate brief periods of synchronous discharges followed by long quiescent periods (Huttenlocher, 1967). Possibly, in the absence of thalamic afferent drive, neurons may default to this slower rhythmic activity determined by intracortical network activity. Consistent with this proposal, isolated cortical tissucs also show these patterned discharges. In the presence of picrotoxin, cortical slices (Hablitz, 1987), hippocampal slices in which the CA3 region has been isolated (Miles et al., 1984), or cultured explants of cortex (Crain, 1966) exhibit rhythmic bursting with a $20-30 \mathrm{sec}$ periodicity as found in primary cortical cultures.

The use of calcium-sensitive probes provides a convenient method for simultaneous monitoring of activity in multiple neurons in a noninvasive manner. Simultaneous records of electrical activity and calcium transients serve to validate this approach. Recent studies by Yuste and Katz (1991) suggest that under certain conditions calcium imaging can also be applied to cortical slice preparations. Thus, these approaches to studying properties of aggregates of cortical neurons in vitro appear to be useful in overcoming the difficult problems associated with studying physiological aspects of cortical development. In addition, the ability to induce synchronous neuronal activity in these cultures and to monitor this activity routinely suggests that this preparation may be useful for studying biochemical events related to synaptic activity. For example, in employing this preparation, we have been able to ascertain the time course of activation and decay of $\mathrm{Ca}^{2+} /$ calmodulin-dependent protein kinase and mitogen-activated protein kinase activity induced by synaptic discharges (Murphy et al., 1992).

\section{References}

Baraban JM, Blatter LA, Wier WG, Murphy TH (1992) Rapid communication between neurons and astrocyte syncytia in primary cortical cultures. Soc Neurosci Abstr 18:1346.

Barker JL, MacDonald JF (1980) Picrotoxin convulsions involve synaptic and nonsynaptic mechanisms on cultured mouse spinal neurons. Science 208:1054-1056.

Benson JA, Adams WB (1987) The control of rhythmic neuronal firing. In: Neuromodulation, the biochemical control of neuronal excitability (Kaczmarek LK, Levitan IB, eds), pp 100-118. New York: Oxford UP.

Blatter LA, Wier WG (1990) Intracellular diffusion, binding, and compartmentalization of the fluorescent calcium indicators indo-1 and fura-2. Biophys J 58:1491-1499.

Brenneman DE, Neale EA, Habig WH, Bowers LM, Nelson PG (1983) Developmental and neurochemical specificity of neuronal deficits 
produced by electrical impulse blockade in dissociated spinal cord cultures. Dev Brain Res 9:13-27.

Cornell-Bell AH, Finkbeiner SM (1991) $\mathrm{Ca}^{2+}$ waves in astrocytes. Cell Calcium 12:185-204.

Cornell-Bell AH, Finkbeiner S, Cooper MS, Smith SJ (1990) Glutamate induces calcium waves in cultured astrocytes: long-range glial signaling. Science $247: 470-473$.

Cox EC, Muller B, Bonhoeffer F (1990) Axonal guidance in the chick visual system: posterior tectal membranes induce collapse of growth cones from the temporal retina. Neuron 4:31-37.

Crain SM (1966) Development of "organotypic" bioelectric activities in central nervous tissues during maturation in culture. Int Rev Neurobiol $9: 1-43$.

Deschenes M, Paradis M, Roy JP, Steriade M (1984) Electrophysiology of neurons of lateral thalamic nuclei in cat: resting properties and burst discharges. J Neurophysiol 51:1196-1219.

Dichter MA (1978) Rat cortical neurons in cell culture: culture methods, cell morphology, electrophysiology, and synapse formation. Brain Res 149:279-293.

Dichter MA, Ayala GF (1987) Cellular mechanisms of epilepsy: a status report. Science 237:157-164.

Fields RD, Yu C, Nelson PG (1991) Calcium, network activity and the role of NMDA channels in synaptic plasticity in vitro. J Neurosci 11:134-146.

Flexner LB, Tyler DB, Gallant LJ (1950) Biochemical and physiological differentiation during morphogenesis. $X$. Onset of electrical activity in developing cerebral cortex of fetal guinea pig. J Neurophysiol 13:427-430.

Fraser SE, Perkel DH (1990) Competitive and positional cues in the patterning of nerve connections. J Neurobiol 21:51-72.

Fregnac Y, Schulz D, Thorpe S, Bienenstock E (1988) A cellular analogue of visual cortical plasticity. Nature 333:367-370.

Furshpan EJ, Potter DD (1989) Seizure-like activity and cellular damage in rat hippocampal neurons in cell culture. Neuron 3:199-207.

Grynkiewicz G, Poenie M, Tsien RY (1985) A new generation of calcium indicators with greatly improved fluorescence properties. J Biol Chem 260:3440-3450.

Gutnick MJ, Connors BW, Prince DA (1982) Mechanisms of neocortical epileptogenesis in vitro. J Neurophysiol 48:1321-1335.

Hablitz JJ (1987) Spontaneous ictal-like discharges and sustained potential shifts in the developing rat neocortex. J Neurophysiol 58:10521065.

Hamill OP, Marty A, Neher E, Sakmann B, Sigworth FJ (1981) Improved patch-clamp techniques for high-resolution current recording from cells and cell-free membrane patches. Pfluegers Arch 391:85100 .

Hebb DO (1949) The organization of behavior. New York: Wiley.

Honore T, Davies SN, Drejer J, Fletcher EJ, Jacobsen P, Lodge D, Nielsen FE (1988) Quinoxalinediones: potent competitive nonNMDA glutamate receptor antagonists. Science 241:701-703.

Huttenlocher PR (1967) Development of cortical neuronal activity in the neonatal cat. Exp Neurol 17:247-262.

Jahnsen H, Llinas R (1984) Electrophysiological properties of guineapig thalamic neurons: an in vitro study. J Physiol (Lond) 349:205226.

Lipton SA (1986) Blockade of electrical activity promotes the death of mammalian retinal ganglion cells in culture. Proc Natl Acad Sci USA 83:9774-9778.

Marangos PJ, Schmechel D, Parma AM, Clark RL, Goodwin FK (1979) Measurement of neuron-specific (NSE) and non-neuronal (NNE) isoenzymes of enolase in rat, monkey and human nervous tissue. J Neurochem 33:319-329.

Meister M, Wong ROL, Baylor DA, Shatz CJ (1991) Synchronous bursts of action potentials in ganglion cells of the developing mammalian retina. Science 252:939-943.
Meyer RL (1983) Tetrodotoxin inhibits the formation of refined retinotopography in goldfish. Dev Brain Res 6:293-298.

Miles R, Wong RKS (1983) Single neurons can influence synchronized population discharge in the CA3 region of the guinea pig hippocampus. Nature 306:371-373

Miles R, Wong RKS, Traub RD (1984) Synchronized afterdischarges in the hippocampus: contribution of local synaptic interactions. Neuroscience 12:1179-1189.

Minta A, Kao J, Tsien RY (1989) Fluorescent indicators for cytosolic calcium based on rhodamine and fluorescein chromophores. J Biol Chem 264:8171-8178.

Misgeld U, Swandulla D (1989) Quisqualate receptor-mediated rhythmic bursting of hypothalamic neurons in dissociated cell culture. Neurosci Lett 98:291-296.

Murphy TH, Baraban JM (1990) Glutamate toxicity in immature cortical neurons precedes development of glutamate receptor currents. Dev Brain Res 57:146-150.

Murphy TH, Schnaar RL, Coyle JT, Sastre A (1988) Glutamate cytotoxicity in a neuronal cell line is blocked by membrane depolarization. Brain Res 460:155-160.

Murphy TH, Worley PF, Baraban JM (1991a) L-type voltage sensitive calcium channels mediate synaptic activation of immediate early genes. Neuron 7:625-635.

Murphy TH, Worley PF, Nakabeppu Y, Christy B, Gastel J, Baraban JM (1991b) Synaptic regulation of immediate early gene expression in primary cultures of cortical neurons. J Neurochem 57:1862-1872.

Murphy TH, Bhat RV, Fiore R, Baraban JM (1992) Calcium calmodulin dependent protein kinase and MAP kinase are differentially regulated by synaptic activity. Soc Neurosci Abstr 18:1091.

Peacock JH (1979) Electrophysiology of dissociated hippocampal cultures from fetal mice. Brain Res 169:247-260.

Pedley TA. Traub RD (1990) Physiological basis of the EEG. In: Current practice of clinical electroencephalography, 2d ed (Daly DD, Pedley TA, eds), pp 107-137. New York, Raven.

Purves D, Sakmann B (1974) Membrane properties underlying spontaneous activity of denervated muscle fibres. J Physiol (Lond) 239: 125-153.

Schilling K, Dickinson MH, Connor JA, Morgan JI (1991) Elcctrical activity in cerebellar cultures determines Purkinje cell dendritic growth patterns. Neuron 7:891-902.

Schmidt JT, Edwards DL (1983) Activity sharpens the map during the regeneration of the retinotectal projection in goldfish. Brain Res 209:29-39.

Shatz CJ (1990) Impulse activity and the patterning of connections during CNS development. Neuron 5:745-756.

Snead OC III, Stephens HI (1983) Ontogeny of cortical and subcortical electroencephalographic events in unrestrained neonatal and infant rats. Exp Neurol 82:249-269.

Stryker MP, Strickland SL (1984) Physiological segregation of ocular dominance columns depends on the pattern of afferent electrical activity. Invest Ophthalmol Vis Sci [Suppl] 25:278.

Traub RD, Knowles WD, Miles R, Wong RKS (1984) Synchronizcd afterdischarges in the hippocampus: simulation studies of the cellular mechanism. Neuroscience 12:1191-1200.

Wier WG, Blatter LA (1991) $\mathrm{Ca}^{2+}$-oscillations and $\mathrm{Ca}^{2+}$-waves in mammalian cardiac and vascular smooth muscle cells. Cell Calcium $12: 241-254$

Wong EHF, Kemp JA, Priestly T, Knight AR, Woodruff GN, Iversen LL (1986) The anticonvulsant MK-801 is a potent $N$-methyl-Daspartate antagonist. Proc Natl Acad Sci USA 83:7104-7108.

Yuste R, Katz LC (1991) Control of postsynaptic $\mathrm{Ca}^{2+}$ influx in developing neocortex by excitatory and inhibitory neurotransmitters. Neuron 6:333-344. 